\title{
Clinical and molecular genetic characterization of familial MECP2 duplication syndrome in a Chinese family
}

Xiaoyan $\mathrm{Li}^{1,2 \dagger}{ }^{+}$, Hua Xie ${ }^{2,3+}$, Qian Chen ${ }^{4}$, Xiongying Yu' ${ }^{1}$, Zhaoshi $\mathrm{Yi}^{1}$, Erzhen $\mathrm{Li}^{4}$, Ting Zhang ${ }^{2}$, Jian Wang ${ }^{5}$, Jianmin Zhong ${ }^{1 *}$ and Xiaoli Chen ${ }^{2,3^{*}}$ (D)

\begin{abstract}
Background: Chromosomal duplication at the Xq28 region including the MECP2 gene, share consistent clinical phenotypes and a distinct facial phenotype known as MECP2 duplication syndrome. The typical clinical features include infantile hypotonia, mild dysmorphic features, a broad range of neurodevelopmental disorders, recurrent infections, and progressive spasticity.

Methods: This Chinese MECP2 duplication syndrome family includes six patients (five males and one female), and four asymptomatic female carriers. Two kinds of chips including 4x180K CNV + SNP chip and custom 8x60K CNV chip were used to detect MECP2 duplication, and then fluorescent in situ hybridization (FISH) analysis was performed to identify the exact copy number of MECP2. X-chromosome inactivation (XCl) analysis on AR gene was detected for all female family members, and the microsatellite analysis on MECP2 was used to validate the recombination event on MECP2 region.

Results: The affected male subjects presented with a broad range of neurodevelopmental symptoms (severe intellectual disability, developmental delay, seizure, language deficit, and autism spectrum disorder) as well as facial dysmorphism and other symptoms which were consistent with that of Western patients previous reported. Seizure is reported in Chinese patients for the first time. In addition, we validated three recombination events for the MECP2-duplication allele during maternal transmission due to $\mathrm{X}$ homologous recombination.

Conclusions: We provided the largest known Chinese pedigree with MECP2 duplication syndrome. The detailed clinical description and molecular genetic characterization in all affected family members further delineate the typical phenotype of this genomic disorder in Chinese population.
\end{abstract}

Keywords: Clinical and molecular genetic characterization, Familial MECP2 duplication syndrome, Genomic recombination

\section{Background}

$\mathrm{X}$-linked intellectual disability (XLID) is a group of genetically heterogeneous diseases characterized by cognitive impairment and reduced adaptive skills [1]. XLID can be caused by single nucleotide variants (SNVs) and/ or copy number variants (CNVs) on the $\mathrm{X}$ chromosome

\footnotetext{
*Correspondence: zhongjm@163.com; cxlwx@sina.com

${ }^{\dagger}$ Equal contributors

'Department of Neurology, Jiangxi Children's Hospital, Yangming Road, Donghu District, Nanchang 330006, China

${ }^{2}$ Beijing Municipal Key Laboratory of Child Development and Nutriomics,

Capital Institute of Pediatrics, Room 616, NO. 2, Yabao Road, Chaoyang

District, Beijing 100020, China

Full list of author information is available at the end of the article
}

[2]. For example, the loss-of-function mutation of methyl-CpG-binding protein 2 gene (MECP2) contributes to Rett syndrome [3], while the increased copy number of $M E C P 2$ contributes to $M E C P 2$ duplication syndrome [4].

With the increased usage of chromosomal microarray or other techniques in clinical diagnostic laboratory, $M E C P 2$ duplication can now be detected quickly. Up to 2015, more than 200 patients with $M E C P 2$ duplication syndrome have been described [5-24]. In China, microarray has been applied for clinical genetic diagnosis only in developed region since 2010 [25-27], the exact diagnosis yield of $M E C P 2$ duplication in neurodevelopmental 
disorders is unknown. Only sporadic Chinese patient with $M E C P 2$ duplication have been reported before. In this study, we reported familial MECP2 duplication syndrome in a large Chinese family, in which four male patients and four asymptomatic females were confirmed as carrying MECP2 duplication. Beside the typical neurodevelopmental symptoms such as severe intellectual disability, developmental delay, poor language skills, and autism spectrum disorder (ASD), the symptom generalized tonic-clonic seizure existed consistently in the four male patients. Major non-neurological symptoms, which include recurrent respiratory infections and constipation, existed in all affected male patients. As the third reported case of MECP2 duplication syndrome in Chinese patients, the detailed neurodevelopmental trajectory and facial dysmorphism in this study will further delineate clinical description and molecular genetic characterization of $M E C P 2$ duplication syndrome in Chinese. Of note, one male patient in this family was the fifth male patient ever reported to have survived past 25 years old $[9,10,15]$.

\section{Methods}

Array comparative genomic hybridization (aCGH) analysis Genomic DNA was extracted from peripheral blood for all available family members using the QIAamp DNA Blood Mini Kit (Qiagen, Hilden, Germany). The aCGH was performed according to previously published methods using Agilent Oligonucleotide Microarray [28]. Raw chip data were analyzed via DNA CytoGenomics software (Agilent Technologies Inc., Palo Alto, CA). There are two kinds of aCGH used to detect MECP2 duplication: $4 \times 180 \mathrm{~K}$ CNV + SNP chip [28] and custom 8x60K CNV chip. The custom $8 \times 60 \mathrm{~K} \mathrm{CNV}$ chip was designed in particular to detect any single genetic $\mathrm{CNV}$ on the known $\mathrm{X}$ linked genes (90 genes) [2]. For $8 \times 60 \mathrm{~K} \mathrm{CNV}$ chip, there are 30,000 probes which were designed to cover the entire genome with an average of $30 \mathrm{~kb}$ between adjacent probes, allowing for the detections of 300-500 kb CNV on non-X chromosomes (the validation results had showed that most of recurrent neurodevelopmental disorderrelated CNV can be detected from this customized chip. Under manuscript); meanwhile, high-density probes $(10,000$ probes) were designed for the genomic region of $90 \mathrm{X}$-linked genes. Then, the probes covering each exon of these X-linked genes were checked one-by-one, ensuring that each exonic region (the exon and its flanking $100 \mathrm{bp)}$ contains at least one probe with an average $100 \mathrm{bp}$ between adjacent probes. Finally, the X chromosome contained $35.57 \%$ (21347) of the whole genome probes, and the $90 \mathrm{X}$-linked genes contained 31.39\% (18837) of whole genomic probes. 88\% of the 1502 exons in the X-linked genes were covered by at least three probes, and $70 \%$ of the 1502 exons were covered by at least four probes. All designs were performed on Agilent SureDesign website (https://earray.chem.agilent.com/suredesign/agilent.com).

\section{Multiplex Ligand-dependant probe amplification (MLPA) analysis and FISH analysis}

MLPA probemix P015 (MRC-Holland, Amsterdam, Holland) was used to test $M E C P 2$ duplication in the remaining family members. Those who are not carrying MECP2 duplication as confirmed by $244 \mathrm{~K}$ chip were chosen as controls. The data was analyzed by Genemarker V5.0.14 (SoftGenetics, State College, PA).

In order to identify the exact copy number of $M E C P 2$, we performed FISH for the proband (III:16) by standard procedures using SureFISH Xq28 MECP2 probe (spectrum green, Hg19, ChrX:153,286,406-153,368,945) and SureFISH Xq22.31 STS probe (spectrum red, Hg19, ChrX:7,137,093-7,272,886) (Agilent Technologies Inc., Palo Alto, CA).

\section{X-chromosome inactivation (XCI) analysis on $A R$ and the microsatellite analysis on $M E C P 2$}

$\mathrm{XCI}$ was examined using androgen receptor $(A R)$ methylation assay with minor modifications [29]. The XCI patterns were classified as random (a ratio between 50:50 and 80:20) or skewed (a ratio higher than 80:20). Two aliquots of $500 \mathrm{ng}$ of genomic DNA were incubated at $37{ }^{\circ} \mathrm{C}$ overnight, one with 20 units of the methylationsensitive restriction enzyme HpaII (NEB, Beverly, USA) and the other without. Both products were then used as templates to amplify the (CAG)n small tandem repeat in exon 1 of $A R$ gene.

The microsatellite $23 \times \mathrm{GT}$ within the $M E C P 2$ gene region was chosen to differentiate the $M E C P 2$-duplication allele from the $M E C P 2$-normal allele. This assay was performed on all available family members. The sequence of forward primer used was FAM 5'-TGAGGACAGCCA GAAGGAGT-3', and that of the reverse primer used was 5' -ACACCCCTTTCCTTTGTGTG-3'.

The PCR products were separated according to size using 3730xl Genetic Analyzer (Applied Biosystems, Vernon Hills, Illinois, USA) and were analyzed by GeneMapper 4.0 software.

The study was approved by the ethics committee of Capital Institute of Pediatrics and Jiangxi Children's Hospital. Written informed consent was obtained from the patients' guardian/parent/next of kin for the publication of this report and any accompanying images. Physical and neurological evaluations were completed by a neurologist and a developmental specialist (i.e. QC, JMZ). IQ was measured by Wechsler Intelligence Scale for Children (WISC), DSM-V was used by the neurologist for ASD diagnosis. 


\section{Results}

\section{Clinical information}

This Chinese family includes a total of six patients with neurodevelopment disorders (five males and one female) from four generations (Fig. 1a). Their physical and neurodevelopmental status were evaluated by a neurologist or a clinical geneticist (Table 1). Four male patients exhibited consistent facial dysmorphism (Fig. 1b). ASD was diagnosed in four male patients (III:6, III:16, IV:1, IV:2) based on the DMS-V criteria.

III:16 was the 11-year-old proband born to a healthy non-consanguineous couple and was delivered with polyhydramnios (birth weight was $3900 \mathrm{~g}$, > 90 percentile). He was noted to exhibit developmental delay at the age of 5 months. He raised his head at 8 months old, walked independently at 2 years old, and uttered "Mama" or "Papa" at 3 years old. He had been referred to Jiangxi Children's Hospital several times due to global developmental delay since he was 6 months old, and then transferred to the Affiliated Children's Hospital of Capital Institute of Pediatrics at 11 years old for final diagnosis/treatment. Thus far, he cannot speak any comprehensible phrase or run steadily and eye contact is absent. Central hypotonia was noticed at birth. He developed generalized tonicclonic seizure at 2 years age, which occurs 1-3 times a year and 3-4 min per attack. Developmental regression was noticed after the first seizure attack. His facial dysmorphic features include midfacial hypoplasia, long face, down-slanting palpebral fissures, epicanthus, small mouth, jaw protrusion, low-set ears, and large ear lobes and creases. He experienced recurrent respiratory infections and refractory constipation with bowel movement every 2-4 days. A brain MRI demonstrated corpus callosum dysplasia. Stereotyped movement (hand flapping, looking at his hands, and biting his fingers) was noticed during clinical interview.

III:15 was an older brother of III:16. His delivery and birth was generally normal except for polyhydramnios and low birth weight (2000 g, < 3 centile). He showed developmental delay since he was 7 months old. He could not say "Mama" or "Papa" even after 3 years old. Severe speech deficit was diagnosed at 7 years old because single words were absolutely absent. Since the age of 3 , he had suffered from generalized tonic-clonic seizures frequently. His parents recalled that he developed schizophrenia-like symptom (no contact with family members and repetitive behavior) after multiple onsets of seizure. Beside the neurodevelopmental symptoms, truncal ataxia and unusual gestures were noticed by his parents and recorded in his medical history. He died of a central nervous system infection at 16 years old. His blood sample was not available for genetic testing.

III:6 was born to a non-consanguineous couple, and had normal gestation, birth, and neonatal development (birth weight was $3500 \mathrm{~g}$, > 75 percentile). He presented with developmental delay at 7 months old. He sat and walked steadily at 2 years old, and uttered "Mama" and "Papa" at 5 years old. He suffered from multiple types of seizures (generalized tonic-clonic seizure, myoclonic seizure, nodding attack and drop attack) frequently after 7 years old, and his language ability regressed after the seizure attacks. Stereotyped movement, unusual gestures, hypotonia, and similar dysmorphic features as III:16 were also noticed. Recurrent respiratory infections and constipation occurred occasionally during the first 10 years. He was 25 years old at the time of our last clinical interview, and he had elementary self-care ability.
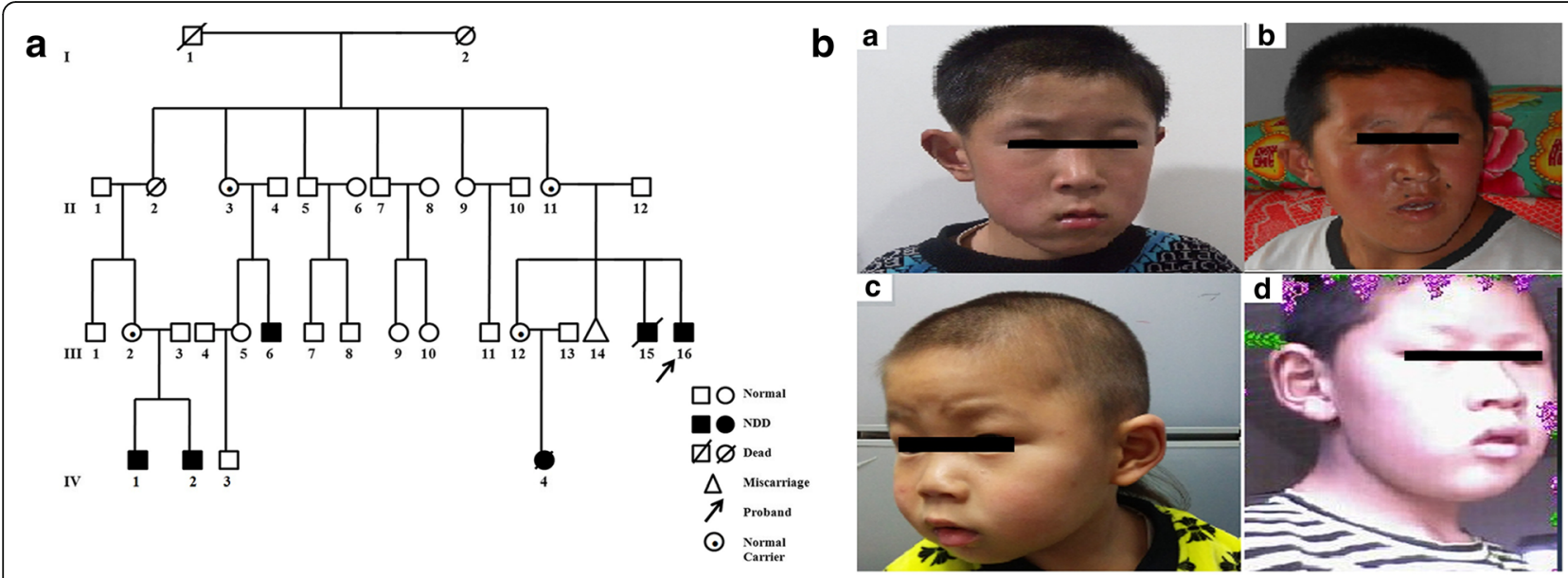

Fig. 1 The Chinese family with MECP2 duplication syndrome. a Pedigree of the Chinese family. $\mathbf{b}$ Facial features of the affected male patients (a. III:16 at 11 years and 2 months old. b. III:6 at 24 years old. c. IV:2 at 2 years and 10 months old. d. IV:1 at 14 years and 8 months old). They show consistent and typical facial features of MECP2 duplication syndrome, such as midface hypoplasia, long face, down-slanting palpebral fissures, epicanthus, small mouth, jaw protrusion, low-set ears, and large ear lobe and crease 
Table 1 The summary of clinical features of the male patients with familial MECP2 duplication

\begin{tabular}{|c|c|c|c|c|c|c|c|c|}
\hline & \multicolumn{6}{|l|}{ Our cases } & \multicolumn{2}{|c|}{$\begin{array}{l}\text { Literature review } \\
\text { (male patients) }\end{array}$} \\
\hline & III:6 & |ll:15 & |ll:16 & $\mathrm{N}: 1$ & $\mathrm{IV}: 2$ & $\%$ & 179 & $\%$ \\
\hline $\begin{array}{l}\text { Age of } \\
\text { enrolled }\end{array}$ & 25 years & NA & $\begin{array}{l}11 \text { years } \\
\text { and } 2 \\
\text { months }\end{array}$ & $\begin{array}{l}14 \text { years and } \\
6 \text { months }\end{array}$ & $\begin{array}{l}2 \text { years } \\
\text { and } \\
6 \text { months }\end{array}$ & & & \\
\hline Age of death & - & 16 years & - & $\begin{array}{l}14 \text { years and } \\
8 \text { months }\end{array}$ & - & & & \\
\hline $\begin{array}{l}\text { Intellectual } \\
\text { disability }\end{array}$ & yes & yes & yes & yes & yes & $100 \%$ & $159 / 160$ & $99.4 \%$ \\
\hline $\begin{array}{l}\text { Delayed } \\
\text { milestones }\end{array}$ & yes & yes & yes & yes & yes & & & \\
\hline $\begin{array}{l}\text { Age of head } \\
\text { control }\end{array}$ & NA & $7-8$ months & $7-8$ months & 3-4 months & $\begin{array}{l}3-4 \\
\text { months }\end{array}$ & & & \\
\hline $\begin{array}{l}\text { Age of } \\
\text { independent } \\
\text { sitting }\end{array}$ & over 2 years & 2 years & 2 years & 8 months & 8 months & & & \\
\hline $\begin{array}{l}\text { Age learned } \\
\text { to walk }\end{array}$ & over 2 years & over 2 years & over 2 years & 3 years & $\begin{array}{l}1 \text { year and } \\
6 \text { months }\end{array}$ & & & \\
\hline Feed difficulty & yes & yes & yes & no & no & & & \\
\hline Seizure & yes & yes & yes & yes & no & $80 \%$ & $97 / 162$ & $59.9 \%$ \\
\hline $\begin{array}{l}\text { Age for first } \\
\text { seizure }\end{array}$ & 7 years & 3 years & 2 years & 10 years & no & & & \\
\hline $\begin{array}{l}\text { Types of } \\
\text { seizures }\end{array}$ & $\begin{array}{l}\text { generalized tonic-clonic } \\
\text { seizure, myoclonic seizure, } \\
\text { nodding attack and drop } \\
\text { attack }\end{array}$ & $\begin{array}{l}\text { generalized } \\
\text { tonic-clonic } \\
\text { seizures }\end{array}$ & $\begin{array}{l}\text { generalized } \\
\text { tonic-clonic } \\
\text { seizures }\end{array}$ & $\begin{array}{l}\text { generalized tonic-clonic } \\
\text { seizure, myoclonic } \\
\text { seizure, nodding attack } \\
\text { and drop attack }\end{array}$ & no & & & \\
\hline Hypotonia & yes & yes & yes & yes & yes & $100 \%$ & $141 / 151$ & $93.4 \%$ \\
\hline $\begin{array}{l}\text { ASD or } \\
\text { autistic } \\
\text { feature }\end{array}$ & yes & yes & yes & yes & yes & $100 \%$ & $30 / 41$ & $73.2 \%$ \\
\hline $\begin{array}{l}\text { Poor or no } \\
\text { eye-to-eye } \\
\text { Contact }\end{array}$ & yes & yes & yes & yes & yes & & & \\
\hline $\begin{array}{l}\text { Delayed } \\
\text { develop peer } \\
\text { relationships }\end{array}$ & yes & yes & yes & yes & yes & & & \\
\hline $\begin{array}{l}\text { Speech lack } \\
\text { or delay }\end{array}$ & yes & yes & yes & yes & yes & & & \\
\hline $\begin{array}{l}\text { Stereotyped } \\
\text { hand } \\
\text { Movement }\end{array}$ & yes & yes & yes & yes & yes & & & \\
\hline $\begin{array}{l}\text { Lack of social } \\
\text { or Emotional } \\
\text { reciprocity }\end{array}$ & yes & yes & yes & yes & yes & & & \\
\hline $\begin{array}{l}\text { Recurrent } \\
\text { respiratory } \\
\text { Infection }\end{array}$ & yes & yes & yes & yes & no & $80 \%$ & $114 / 157$ & $72.6 \%$ \\
\hline Constipation & yes & yes & yes & yes & yes & $100 \%$ & $39 / 103$ & $37.9 \%$ \\
\hline $\begin{array}{l}\text { MECP2 } \\
\text { duplication diagnosis }\end{array}$ & MLPA & $\begin{array}{l}\text { clinical feature } \\
\text { and family-based } \\
\text { linkage analysis }\end{array}$ & array CGH & array CGH & MLPA & & & \\
\hline
\end{tabular}


However, he cannot communicate socially with others, and lacked eye-contact. His IQ scores was less than 30.

IV:1 was the first boy born to non-consanguineous parents after normal gestation, delivery, and neonatal period (birth weight was $4000 \mathrm{~g}$, > 95 percentile). He showed developmental delay since 12 months old; he could walk independently and babble some nonconscious words at 3 years old. He also suffered from hypotonia, seizures, constipation and recurrent respiratory infections as the above affected patients did. The types of seizures included generalized tonic-clonic seizure, myoclonic seizure, nodding attack and drop attack. Developmental regression was noticed after the seizures. A brain MRI demonstrated hypomyelination in the periventricular white matter. He presented with stereotyped movements and eye contact was absent. At the age of 14 years and 6 months, he suffered from a central nervous system infection and died 2 months later as a result. All medical evaluations and genetic testing have been completed before his death.

IV:2 was a younger brother of IV:1 with normal gestation and birth (birth weight was $3500 \mathrm{~g},>75$ percentile). He showed developmental delay since he was 12 months old. For example, he walked with an ataxic gait after 2 years old. Now, at 2 year and 6 months old, he only can say "Mama" and "Papa". Like his brother and the other male patients in his family, he presented with stereotyped movements, little eye contact, hypotonia, and constipation However, he did not suffer from recurrent respiratory infections, developmental regression or seizures. Young age is the possible explanation. A brain MRI demonstrated periventricular leukodystrophy. The electroencephalogram was normal.

IV:4 was a girl born to non-consanguineous parents at normal birth (birth weight was $3000 \mathrm{~g},>25$ percentile). She died of severe pneumonia and myocarditis at the age of 2. According to her parents, during neonatal period, she had a fever with temperature over $39^{\circ} \mathrm{C}$, and her development was significantly delayed compared to that of age-matched peers. She had not raised her head, sit or walked independently at all until her death. Central hypotonia, recurrent respiratory infections and absence of eye contact were recorded in her medical history. She has experienced generalized tonic-clonic seizures since she was 3 months old. A brain MRI before her death demonstrated diffuse low density. No blood sample was available for genetic testing.

\section{Familial MECP2 duplication is identified by aCGH, MLPA and FISH analysis}

The high-density array $(4 \times 180 \mathrm{~K})$ was used for III:16 only. He showed a clinically significant $550 \mathrm{~kb}$ duplication on the Xq28 region (chrX:153,056,054-153,606,328 in the genome build hg19, Fig. 2a). This region contains
24 genes (including $M E C P 2, I R A K 1, L 1 C A M, A V P R 2$, $N A A 10, H C F C 1$, etc). Afterwards, the custom $8 \times 60 \mathrm{~K}$ array was used to test for the same $M E C P 2$ duplication in the others. The custom array ultimately showed that the male patient (IV:1) also harbored the MECP2 duplication (Fig. 2b). Some female family members (II:11, III:2 and III:12) harbored the duplication as well, but others (II:5, II:7, II:9 and III:5) did not. MLPA results confirmed the duplication in patients III: 6 and IV:2 and in family member II:3 (Additional file 1: Figure S1). In total, four female carriers (II:3, II:11, III:2 and III:12) and four male patients (III:6, III:16, IV:1 and IV:2) in the pedigree harboured the duplication demonstrating that it was maternally inherited. The dual signal of Xq28 region in patient III:16 confirmed that the patient harbors a MECP2 duplication rather than a triplication (Fig. 2c). Considering that tandem arrangement is the common form of $M E C P 2$ duplication, we tried to amplify the junction fragment using the breakpoint-specific primers. However, we were unable to map out the sequence feature due to the enriched repeat in this region.

\section{Skewed XCl patterns and inter-chromosomal homologous recombination during $M E C P 2$ and $A R$ region}

Analysis of XCI patterns on all the female family members (Additional file 2: Figure S2) showed that the XCI patterns in the female non-carriers were all random (II:9 and III:5), but that of the female carriers were all skewed (II:3, II:11, III:2 and III:12). However, the predominantly inactivated allele of $A R$ gene in two female carriers from the same core family (II:3 and II:11) was not the same. II:3 had inactivated maternally inherited allele279 while II:11 had inactivated maternally inherited allele285 (Additional file 2: Figure S2B, C). Accordingly, we tested for the alleles of $A R$ gene in all male patients (III:6, III:16, IV:1 and IV:2) and found that the male patients did not carry the same allele. More importantly, two male patients from the same core family (brothers IV:1 and IV:2) carried different maternally inherited alleles (IV:1 carried allele-293 and IV:2 carried allele-274, see Additional file 2: Figure S2A). On the basis of above data, we inferred that the inter-chromosomal homologous recombination occurred on the MECP2-duplication region.

In order to validate the occurrence of homologous recombination in the $M E C P 2$ region, we chose the microsatellite $23 \times \mathrm{GT}$ within the $M E C P 2$ gene as the marker for $M E C P 2$ duplication. We found that allele292 of microsatellite $23 \times$ GT was shared by all of the $M E C P 2$ duplication carriers (Additional file 3: Figure S3), which highlighted the close linkage of $M E C P 2 \mathrm{du}-$ plication to allele-292. Furthermore, after analyzing the relationship between $A R$-specific and $M E C P 2$-specific microsatellites in every family member, we inferred that the MECP2-duplication allele was exchanged with 


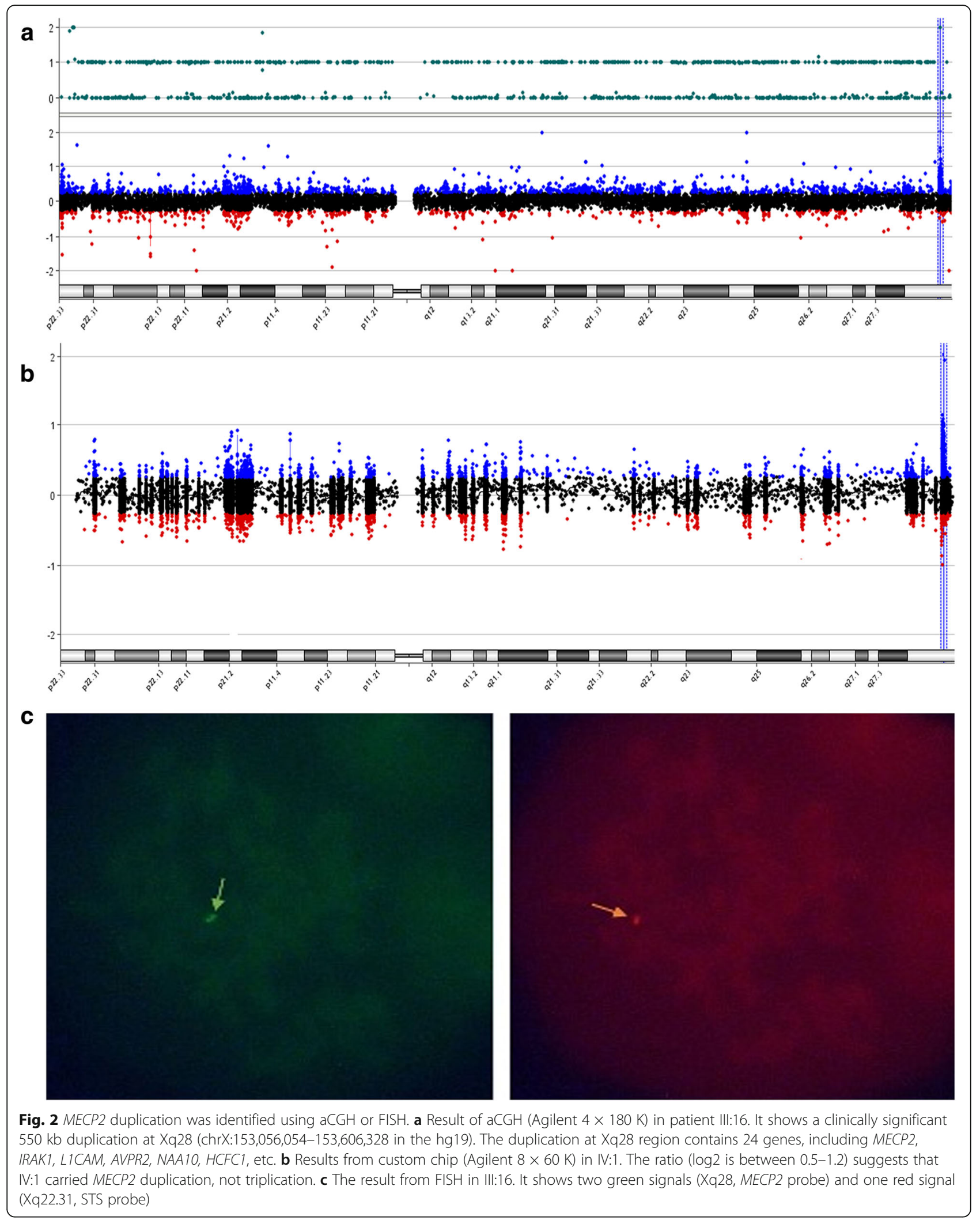


MECP2-normal allele by inter-chromosomal homologous recombination during meiosis, resulting in different microsatellite of $A R$ gene in the MECP2-duplication allele (Fig. 3). This proved that there has been three separate $M E C P 2$ recombination events which occurred during three maternal transmissions (specifically, II:3 and II:11 from I:2; III:5 and III:6 from II:3; and IV:1and IV:2 from III:2).

\section{Discussion}

Methyl-CpG binding protein 2 (MECP2) is a transcriptional repressor that functions by binding directly to methylated CpG dinucleotides and recruiting co-repressor proteins such as histone deacetylases and Sin3a to the promoters of target genes [30, 31]. MECP2 duplication syndrome refers to the duplication of $M E C P 2$ which is located at Xq28. MECP2 duplication syndrome was first described in a pedigree with five male patients presenting with severe intellectual disability in 1997 [32]. It was then recognized as a disorder of genomic imbalance using realtime PCR in 2005 [4]. MECP2 duplication is now recognized as one cause of neurodevelopmental disorders. The genomic copy variant evaluation study from more than 700 patients with unexplained mental retardation suggested the prevalence of the $M E C P 2$ duplication syndrome in male and female patients is approximately 1 and $0.3 \%$, respectively [12].
As a rare and severe genomic imbalance disorder, $M E C P 2$ duplication syndrome is characterized by a broad range of neurodevelopmental abnormalities (severe intellectual disability, developmental delay, seizure, speech delay/deficit, ASD), as well as hypotonia, recurrent respiratory infections, and facial dysmorphism [11]. Recently, Lim et al. examined 56 cases (49 males and 7 females) with $M E C P 2$ duplication syndrome and expanded the phenotypic spectrum of this syndrome, such as scoliosis and gastrointestinal problems [33]. Two Chinese patients with MECP2 duplication have been reported previously, and they showed that Chinese patients present similarly as patients in western counties $[6,7]$. However, these reports have only studied small pedigrees, and do not contain enough information to help Chinese pediatricians distinguish patients with $M E C P 2$ duplication syndrome from patients with other unknown neurodevelopmental disorders. In this study, we described the detailed clinical and molecular genetic characteristics of a Chinese familial MECP2 duplication. After testing all available members, we identified nine family members with $M E C P 2$ duplication. Although the DNA of patient III:15 was not available for testing, his clinical characteristics and family-based linkage analysis suggested he had $M E C P 2$ duplications syndrome too. It is one of the largest pedigrees of familial MECP2 duplication, and is the largest Chinese pedigree thus far. This pedigree includes five male patients and four asymptomatic female carriers.

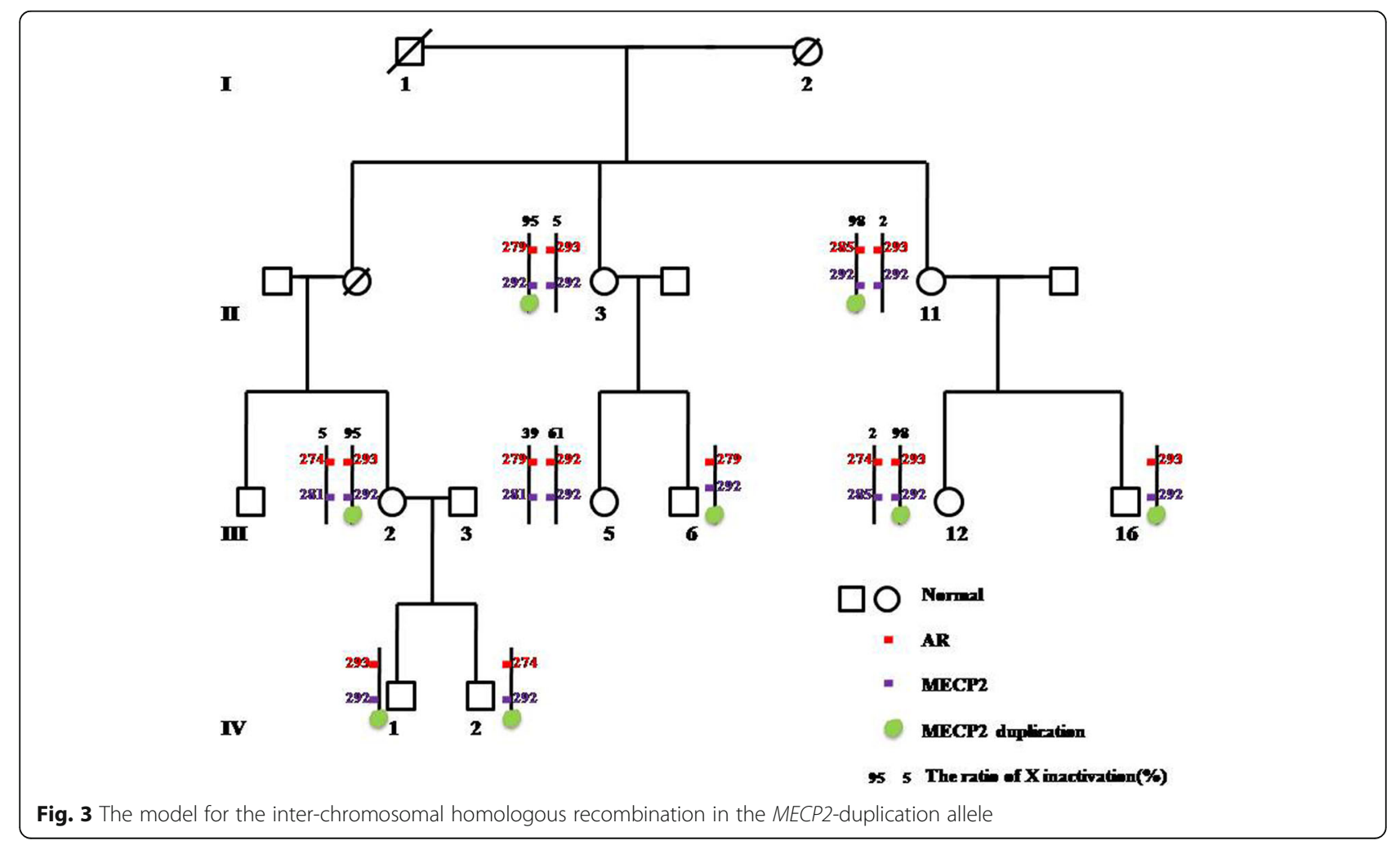


We reviewed 17 related publications on $M E C P 2$ duplication syndrome and analyzed the prevalence of major medical issues from 179 male patients (See Table 1) [6, 7, 9-24]. Core symptoms of MECP2 duplication syndrome include developmental delay $(100 \%)$, severe intellectual disability (99.4\%), hypotonia (93.4\%), ASD or autistic feature (73.2\%), recurrent infections (72.6\%), and seizure/epilepsy (59.9\%). All male patients in this Chinese family presented with the above major symptoms (See Table 1). The consistent neurodevelopmental trajectory and facial dysmorphism in these five male patients further delineated clinical description and molecular genetic characterization of Chinese $M E C P 2$ duplication syndrome. In addition, seizure was reported for the first time in a patient of Chinese Han ethinicity. In particular, four out of the five $(4 / 5,80 \%)$ male patients presented generalized tonic-clonic seizure.

After reviewing all case reports on $M E C P 2$ duplication syndrome published during last 5 years, only four male patients were reported to have survived beyond 25 years $[9,10,15]$. Patient III:6 in our study has survived past 25 years old. He did not present any differently than the patients who have died younger. Continuous clinical interviews and physical/neurodevelopmental evaluations will be performed on him in the future, so that we can learn about the natural pathogenic progression of $M E C P 2$ duplication syndrome. Of note, there have been reports of patients with $M E C P 2$ triplication [18, 34]. The major clinical manifestations of $M E C P 2$ triplication syndrome are similar to that of $M E C P 2$ duplication syndrome except for the additional symptom of macrocephaly. Fittingly, male patients in this study did not present with macrocephaly.

The majority of $M E C P 2$ duplication are inherited, de novo mutations are rare $[22,23]$. Most cases are inherited maternally; paternal inheritance is exceedingly rare, and there have been only four reported cases of paternal inheritance, in which the male patients inherited the gene duplication from an unbalanced $\mathrm{X} / \mathrm{Y}$ translocation $[10,22]$. As an $\mathrm{X}$-linked disorder, males are predominantly affected. Females with one copy of MECP2 duplication are usually asymptomatic carriers as XCI is often skewed and preferentially inactivates the duplicationbearing $\mathrm{X}$ chromosome [11]. However, female patients with $M E C P 2$ duplication have been reported sporadically $[35,36]$. The molecular genetic pathogenesis of symptomatic female patients included 1) unbalanced translocation between $\mathrm{X}$ chromosome and autosome, 2) no skewing of X-chromosome inactivation and 3) skewed $\mathrm{XCI}$ where the normal chromosome is preferentially inactivated [35-37]. The symptoms in affected females are the same as those in affected males [2, 10, 12, 14, 38]. In our study, female patient (IV:4) presented with some symptoms of $M E C P 2$ duplication syndrome as the five male patients. She died at the age of 2 years and 10 days. Given the similarities in the clinical presentation and early death, we believe that she was an affected patient although no sample was available for genetic testing. We speculate that the skewed XCI on the normal X chromosome caused her to be symptomatic.

Differential methylation at the $5^{\prime}$ portions of genes on $\mathrm{X}$ chromosome is considered to be one of the primary factors involved in XCI [29]. The human $A R$ gene is usually selected as the marker for XCI because it is unique in having a (CAG)n repeat in exon 1, and is highly pleomorphic, with a heterozygosity of $90 \%$. However, $A R$ gene is located at $\mathrm{Xq12}$, which is $90 \mathrm{Mb}$ away from $M E C P 2$ region, located at $\mathrm{Xq} 28$, and the homologous recombination or crossover between the parental alleles can occur during meiosis. As a result of the interchromosomal homologous recombination in $M E C P 2$ region, the (CAG)n repeat marker of $A R$ gene is not consistent with that of MECP2-duplication allele in offspring. Our study confirmed three recombination events for the $M E C P 2$-duplication allele during maternal transmission due to homologous recombination. Therefore, we should be careful not to ignore inter-chromosomal homologous recombination when studying a gene located on Xq28 (like $M E C P 2$ ) while using $A R$ gene as a marker for XCI.

\section{Conclusions}

We described the detailed clinical and genetic characterization of a large Chinese family with familial MECP2 duplication syndrome. The consistency in clinical presentation in affected family members delineate the typical phenotype of this genomic disorder in Chinese population, which include severe intellectual disability, ASD, seizures, respiratory infections, and constipation. Our report will help clinical neurologists recognize the disorder and distinguish it from other unknown neurodevelopment disorders. Meanwhile, although we described the clinical history for each of our patients, the few MECP2 duplication cases reported from China are insufficient to allow comparison of phenotypes between Asian and Caucasian patients. Collaboration between countries and regions is urgently needed in order to study the natural history of rare diseases such as $M E C P 2$ duplication on a global scale [39].

\section{Additional files}

Additional file 1: Figure S1. The MLPA result of the family members. (PDF 263 kb)

Additional file 2: Figure S2. X-chromosome inactivation results analyzed using (CAG)n STR of AR gene. (PDF $221 \mathrm{~kb}$ )

Additional file 3: Figure S3. The results for microsatellite $23 \times \mathrm{GT}$ of MECP2 gene. (PDF $182 \mathrm{~kb}$ ) 


\section{Abbreviations}

aCGH: Array comparative genomic hybridization; AR: Androgen receptor; ASD: Autism spectrum disorder; CNVs: Copy number variants; FISH: Fluorescent in situ hybridization; MECP2: Methyl-CpG-binding protein 2 gene; MLPA: Multiplex Ligand-dependant Probe amplification; SNVs: Single nucleotide variants; $X \mathrm{Cl}$ : $\mathrm{X}$-Chromosome inactivation; XLID: X-linked intellectual disability

\section{Acknowledgements}

We sincerely thank all the family members who contributed to the study. We appreciate Sydney Song, the MD/PhD Candidate of Case Western Reserve University for her help in editing the manuscript.

\section{Funding}

This work is partially funded by the Capital Health Research and Development of Special (2014-2-1131), the National Nature Science Fund [81100841, 81370708 and 31671310 to XLC, 81401207 to Hua Xie], Beijing Nature Science Fund [7162029 to XLC], the advanced Personnel Training Program of Beijing Municipal Health Bureau to XLC, Beijing nova program interdisciplinary collaborative project (xxjc201717) to XLC.

\section{Availability of data and materials}

The data that support the findings are all available in this published article and its supplementary information files.

\section{Authors' contributions}

XLC designed the study, XYL, HX, XLC and JW performed DNA extraction, array experiment, MLPA, STR genotyping and data analysis, XYL, XLC and HX performed manuscript writing. JW analyzed and interpreted of data of FISH. QC, XYY, ZSY, EZL and JMZ helped in patients and family members' recruitment and clinical checkup and obtained a genetics questionnaire. TZ gave key suggestions for design and manuscript writing. All authors read and approved the final manuscript.

\section{Ethics approval and consent to participate}

All research was approved by the ethics committee of Capital Institute of Pediatrics (SHERLL 2015069). The participants or the guardian/parent/next of kin on behalf of the minors under the age of 16 signed informed consent forms.

\section{Consent for publication}

The written informed consent was obtained from the participants or the patients' guardian/parent/next of kin for the publication of related clinical information and images.

\section{Competing interests}

The authors declare that they have no competing interests.

\section{Publisher's Note}

Springer Nature remains neutral with regard to jurisdictional claims in published maps and institutional affiliations.

\section{Author details}

'Department of Neurology, Jiangxi Children's Hospital, Yangming Road, Donghu District, Nanchang 330006, China. ${ }^{2}$ Beijing Municipal Key Laboratory of Child Development and Nutriomics, Capital Institute of Pediatrics, Room 616, NO. 2, Yabao Road, Chaoyang District, Beijing 100020, China. ${ }^{3}$ Department of Medical Genetics, Capital Institute of Pediatrics, Beijing, China. ${ }^{4}$ Department of Neurology, Affiliated Children's Hospital of Capital Institute of Pediatrics, Beijing, China. ${ }^{5}$ Department of Laboratory Medicine, Shanghai Children's Medical Center, Shanghai Jiaotong University School of Medicine, Shanghai, China

\section{Received: 17 July 2016 Accepted: 24 October 2017}

\section{Published online: 15 November 2017}

\section{References}

1. Bassani S, Zapata J, Gerosa L, Moretto E, Murru L, Passafaro M. The neurobiology of X-linked intellectual disability. The Neuroscientist. 2013, 19(5):541-52.

2. Gecz J, Shoubridge C, Corbett M. The genetic landscape of intellectual disability arising from chromosome X. Trends Genet. 2009;25(7):308-16.
3. Amir RE, Van den Veyver IB, Wan M, Tran CQ, Francke U, Zoghbi HY. Rett syndrome is caused by mutations in X-linked MECP2, encoding methylCpG-binding protein 2. Nat Genet. 1999;23(2):185-8.

4. Meins M, Lehmann J, Gerresheim F, Herchenbach J, Hagedorn M, Hameister $\mathrm{K}$, et al. Submicroscopic duplication in Xq28 causes increased expression of the MECP2 gene in a boy with severe mental retardation and features of Rett syndrome. J Med Genet. 2005;42(2):e12.

5. Bauer M, Kolsch U, Kruger R, Unterwalder N, Hameister K, Kaiser FM, et al. Infectious and immunologic phenotype of MECP2 duplication syndrome. J Clin Immunol. 2015;35(2):168-81.

6. Zhang Q, Zhao Y, Yang Y, Bao X. MECP2 duplication syndrome in a Chinese family. BMC Med Genet. 2015;16:112.

7. Xu X, Xu Q, Zhang Y, Zhang X, Cheng T, Wu B, et al. A case report of Chinese brothers with inherited MECP2-containing duplication: autism and intellectual disability, but not seizures or respiratory infections. BMC Med Genet. 2012;13:75

8. Van Esch H, Bauters M, Ignatius J, Jansen M, Raynaud M, Hollanders K, et al. Duplication of the MECP2 region is a frequent cause of severe mental retardation and progressive neurological symptoms in males. Am J Hum Genet. 2005;77(3):442-53.

9. Honda S, Satomura S, Hayashi S, Imoto I, Nakagawa E, Goto Y, et al. Concomitant microduplications of MECP2 and ATRX in male patients with severe mental retardation. J Hum Genet. 2012:57(1):73-7.

10. Hanchard NA, Carvalho CM, Bader P, Thome A, Omo-Griffith L, del Gaudio $D$, et al. A partial MECP2 duplication in a mildly affected adult male: a putative role for the $3^{\prime}$ untranslated region in the MECP2 duplication phenotype. BMC Med Genet. 2012;13:71.

11. Van Esch H. MECP2 duplication syndrome. Mol Syndromology. 2012;2(3-5):128-36

12. Shimada S, Okamoto N, Ito M, Arai Y, Momosaki K, Togawa M, et al. MECP2 duplication syndrome in both genders. Brain Dev. 2013;35(5):411-9.

13. Ramocki MB, Tavyev YJ, Peters SU. The MECP2 duplication syndrome. Am J Med Genet A. 2010;152A(5):1079-88.

14. Shimada S, Okamoto N, Hirasawa K, Yoshii K, Tani Y, Sugawara M, et al. Clinical manifestations of Xq28 functional disomy involving MECP2 in one female and two male patients. Am J Med Genet A. 2013;161A(7):1779-85.

15. Vignoli A, Borgatti R, Peron A, Zucca C, Ballarati L, Bonaglia C, et al. Electroclinical pattern in MECP2 duplication syndrome: eight new reported cases and review of literature. Epilepsia. 2012;53(7):1146-55.

16. Trobaugh-Lotrario A, Martin J, Lopez-Terrada D. Hepatoblastoma in a male with MECP2 duplication syndrome. Am J Med Genet A. 2016:170(3):790-1.

17. Caumes R, Boespflug-Tanguy O, Villeneuve N, Lambert L, Delanoe C, Leheup $B$, et al. Late onset epileptic spasms is frequent in MECP2 gene duplication: electroclinical features and long-term follow-up of 8 epilepsy patients. Eur J Paediatr Neurol. 2014;18(4):475-81.

18. Tang SS, Fernandez D, Lazarou LP, Singh R, Fallon P. MECP2 triplication in 3 brothers - a rarely described cause of familial neurological regression in boys. Eur J Paediatr. 2012;16(2):209-12.

19. Fernandez RM, Nunez-Torres R, Gonzalez-Meneses A, Antinolo G, Borrego S. Novel association of severe neonatal encephalopathy and Hirschsprung disease in a male with a duplication at the Xq28 region. BMC Med Genet. 2010;11:137.

20. Peters SU, Hundley RJ, Wilson AK, Warren Z, Vehorn A, Carvalho CM, et al. The behavioral phenotype in MECP2 duplication syndrome: a comparison with idiopathic autism. Autism Res. 2013;6(1):42-50.

21. Fukushi D, Yamada K, Nomura N, Naiki M, Kimura R, Yamada Y, et al. Clinical characterization and identification of duplication breakpoints in a Japanese family with Xq28 duplication syndrome including MECP2. Am J Med Genet A. 2014;164A(4):924-33.

22. Lin DS, Chuang TP, Chiang MF, Ho CS, Hsiao CD, Huang YW, et al. De novo MECP2 duplication derived from paternal germ line result in dysmorphism and developmental delay. Gene. 2014;533(1):78-85.

23. Neira VA, Romero-Espinoza P, Rojas-Martinez A, Ortiz-Lopez R, CordovaFletes C, Plaja A, et al. De novo MECP2 disomy in a Mexican male carrying a supernumerary marker chromosome and no typical Lubs syndrome features. Gene. 2013;524(2):381-5.

24. de Palma L, Boniver C, Cassina M, Toldo I, Nosadini M, Clementi M, et al. Eating-induced epileptic spasms in a boy with MECP2 duplication syndrome: insights into pathogenesis of genetic epilepsies. Epileptic Disord. 2012;14(4):414-7.

25. Xu Q, Goldstein J, Wang P, Gadi IK, Labreche H, Rehder C, et al. Chromosomal microarray analysis in clinical evaluation of 
neurodevelopmental disorders-reporting a novel deletion of SETDB1 and illustration of counseling challenge. Pediatr Res. 2016;80(3):371-81.

26. Chen XL, Guo J, Wang J, Wang LW, Ding XY, Zhang T, et al. Genomic copy number variations in children with unexplained mental retardation and developmental delay detected by array-comparative genomic hybridization. Chinese journal of evidence-based. Pediatrics. 2010;5(2):85-93.

27. Yuan H, Zhu J, Deng X, Chen M, Li X, Li Q, et al. Chromosomal microarray analysis of 2000 pediatric cases. Chinese. J Med Genet. 2016;33(2):247-51.

28. Shen Y, BL W. Microarray-based genomic DNA profiling technologies in clinical molecular diagnostics. Clin Chem. 2009;55(4):659-69.

29. Allen RC, Zoghbi HY, Moseley AB, Rosenblatt HM, Belmont JW. Methylation of Hpall and Hhal sites near the polymorphic CAG repeat in the human androgen-receptor gene correlates with X chromosome inactivation. Am J Hum Genet. 1992;51(6):1229-39.

30. Jones PL, Veenstra GJ, Wade PA, Vermaak D, Kass SU, Landsberger N, et al. Methylated DNA and MeCP2 recruit histone deacetylase to repress transcription. Nat Genet. 1998;19(2):187-91.

31. Nan X, Ng HH, Johnson CA, Laherty CD, Turner BM, Eisenman RN, et al. Transcriptional repression by the methyl-CpG-binding protein MeCP2 involves a histone deacetylase complex. Nature. 1998;393(6683):386-9.

32. Pai GS, Hane B, Joseph M, Nelson R, Hammond LS, Arena JF, et al. A new X linked recessive syndrome of mental retardation and mild dysmorphism maps to Xq28. J Med Genet. 1997;34(7):529-34.

33. Lim Z, Downs J, Wong K, Ellaway C, Leonard H. Expanding the clinical picture of the MECP2 duplication syndrome. Clin Genet. 2016. https://doi. org/10.1111/cge. 12814

34. del Gaudio D, Fang P, Scaglia F, Ward PA, Craigen WJ, Glaze DG, et al. Increased MECP2 gene copy number as the result of genomic duplication in neurodevelopmentally delayed males. Genet Med. 2006;8(12):784-92.

35. Fieremans N, Bauters M, Belet S, Verbeeck J, Jansen AC, Seneca S, et al. De novo MECP2 duplications in two females with intellectual disability and unfavorable complete skewed X-inactivation. Hum Genet. 2014;133(11): 1359-67.

36. Auber B, Burfeind $P$, Thiels $C$, Alsat EA, Shoukier M, Liehr T, et al. An unbalanced translocation resulting in a duplication of Xq28 causes a Rett syndrome-like phenotype in a female patient. Clin Genet. 2010;77(6):593-7.

37. Sanlaville D, Prieur M, de Blois MC, Genevieve D, Lapierre JM, Ozilou C, et al. Functional disomy of the Xq28 chromosome region. Eur J Hum Genet. 2005:13(5):579-85

38. Scott Schwoerer J, Laffin J, Haun J, Raca G, Friez MJ, Giampietro PF. MECP2 duplication: possible cause of severe phenotype in females. Am J Med Genet A. 2014;164A(4):1029-34

39. Louise S, Fyfe S, Bebbington A, Bahi-Buisson N, Anderson A, Pineda M, et al. InterRett, a model for international data collection in a rare genetic disorder. Res Autism Spectr Disord. 2009;3(3)

\section{Submit your next manuscript to BioMed Central and we will help you at every step:}

- We accept pre-submission inquiries

- Our selector tool helps you to find the most relevant journal

- We provide round the clock customer support

- Convenient online submission

- Thorough peer review

- Inclusion in PubMed and all major indexing services

- Maximum visibility for your research

Submit your manuscript at www biomedcentral.com/submit

) Biomed Central 